\title{
How Has the Current Curative Expenditure of Noncommunicable Diseases Changed? Evidence From China in 2017-2019
}

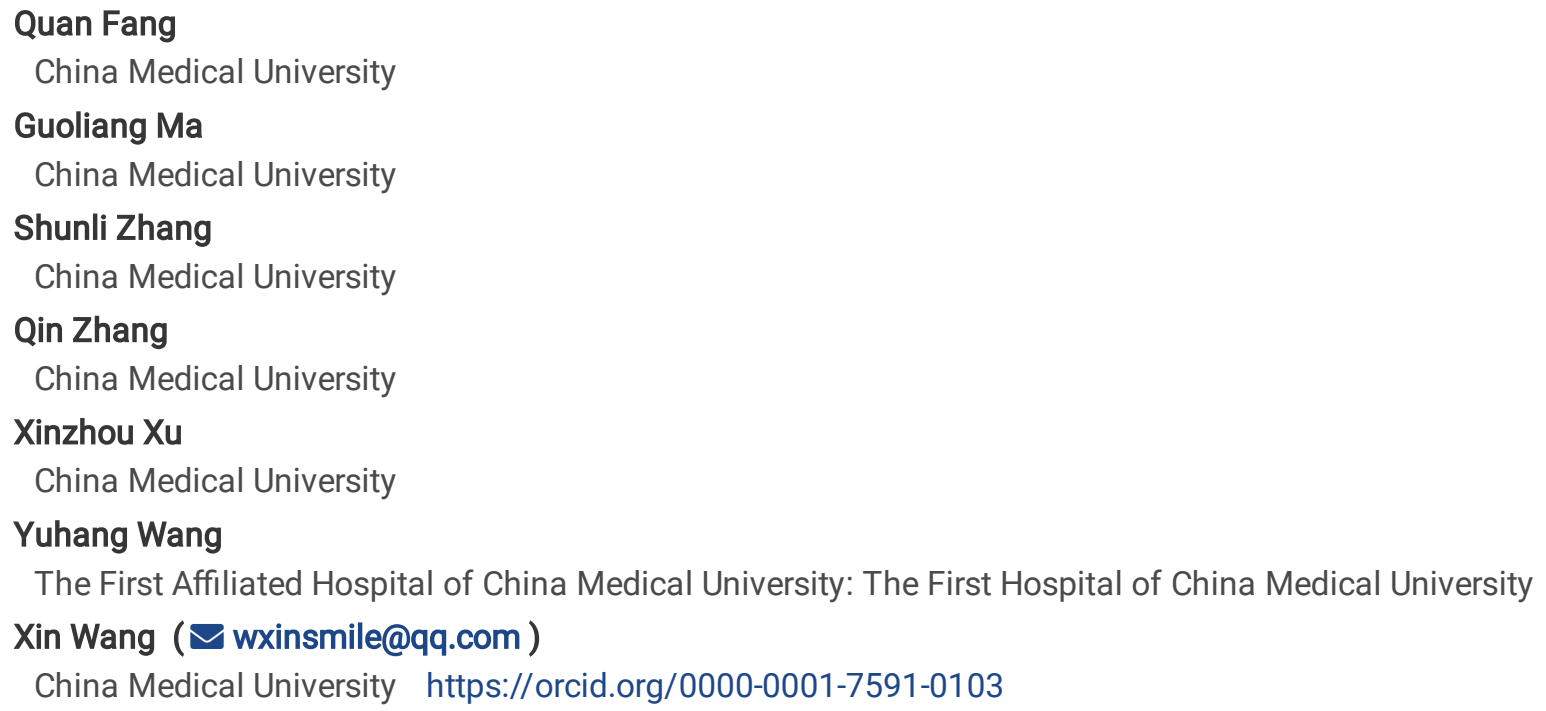

Keywords: Noncommunicable diseases (NCDs), "System of Health Accounts 2011"(SHA 2011), Economic burden, Current curative expenditure (CCE), China

Posted Date: August 26th, 2021

DOI: https://doi.org/10.21203/rs.3.rs-824133/v1

License: (1) (1) This work is licensed under a Creative Commons Attribution 4.0 International License. Read Full License 


\section{Abstract}

Background: Noncommunicable diseases (NCDs) are the leading causes of morbidity and mortality worldwide. Understanding the distribution of diseases can provide a basis for policy formulation and intervention. This study analyses the current curative expenditure (CCE) of NCDs in China to provide health policy advice.

Methods: Data were collected by multi-stage stratified random sampling from 2017-2019. The medical expenses of patients with NCDs were calculated based on "System of Health Accounts 2011"(SHA 2011), Analyze from funding sources, dimensions of institutional flow, and financing scheme. Linear regression analysis was conducted by controlling factors influencing hospitalization expenses. All analyses were performed by STATA 15.0 .

Results: 408 institutions and 8,104,233 valid items were included in the study. The CCE of NCDs was 14.205 billion China Yuan (CNY) in 2017, 15.914 billion CNY in 2018, and 18.055 billion CNY in 2019 . More than $60 \%$ came from public financing. The proportion of family health financing continued to decline, reaching $31.16 \%$ in 2019 . The expenditures were mainly in general hospitals, above $70 \%$. Elderly patients account for the majority. Diseases of the circulatory system, Diseases of the digestive system, and Neoplasms were the main NCDs. Year, age, gender, length of stay, surgery, insurance, and institution level were the factors affecting hospitalization expenses.

Conclusions: NCDs are the main CCE of diseases in China, and their resources are not allocated reasonably. To reduce the CCE of NCDs, the government needs to optimize resource allocation and rationalize institutional flows and functions.

\section{Background}

Due to the gradual transition of the spectrum of the disease, noncommunicable diseases (NCDs) are now the leading causes of morbidity and mortality worldwide [1-2]. According to the World Health Organization (WHO), NCDs currently cause more deaths than all other causes combined. In 2012, 56 million people died worldwide, 38 million (68\%) were caused by NCDs, and NCD deaths are projected to reach 52 million by 2030. The situation is worse in low-and middle-income countries (LMICs), Nearly three-quarters of these NCDs deaths occurred in LMICs, and the death rate is about 1.6 times higher than in high-income countries [3-4]. It is also a considerable challenge even among the wealthiest countries, which are members of the Organization for Economic Co-operation and Development [5]. NCDs are among the most prevalent and costly health conditions in the United States. Besides, NCDs also have a massive impact on families and poverty [6-7]. Especially for the uninsured and the elderly [8].

NCDs have a long incubation period and cannot heal after the onset or are challenging to heal [9-11], which raised the demand for long-term care expenditures. During 2001-2025, cumulative economic losses due to NCDs under a "business as usual" scenario in LMICs have been estimated at US\$ 7 trillion, which is sum far outweighs the annual US\$ 11.2 billion cost of implementing a set of high-impact interventions to reduce the NCDs economic burden [3]. A recent study estimates that over the next 20 years, at the global level, NCDs will cost more than US\$ 47 trillion and will push millions of people below the poverty line[12]. As a result, many countries worldwide have made NCDs a priority for Universal Health Coverage, which is considered an essential element of sustainable human development goals [13-16].

China is the largest developing country in the world. It had 6.6 million deaths from chronic diseases in 2015, the highest of any country in the world [17]. In addition to the excessive death toll related to the population base, China's ageing population, especially the elderly over the age of 60 , is related to the increase. A study showed that $92 \%$ of the elderly had at least one NCDs, and $77 \%$ had two NCDs [18]. China has more than 230 million people over the age of 60 , accounting for $16.7 \%$ of the total population in 2016[19]. Since 2010 , the elderly population has increased by $29.5 \%$ [20]. Older adults with good household assets and access to medical services were less likely to experience multimorbidity [21]. Dalian is located in the southern northeast China. It has a higher proportion of people over the age of 60 than the whole country, making it difficult to prevent and control NCDs [22-23].

Previous work was focused on specific types of NCDs or particular regions of the world [24-26]. Although this can provide a more accurate intervention scheme for specific NCDs, it is easy to waste resources if it is not grasped at a higher level because more people have more than one type of NCDs [18]. In this study, we collected expenditure information of NCDs patients in Dalian and used "System of Health Account 2011" (SHA 2011) to count each part of curative expenditure[27-28]. As a result, China began to adopt the new accounting system "SHA 2011" in 2014. SHA 2011 further developed additional analytical possibilities. It provides a

Page 2/13 
breakdown of input factors and associated costs for health care products and services. For example, based on the basic characteristics of patients, we can calculate the medical costs under different ages, gender, and disease categories. Moreover, it can make the more accurate division between expenditure and input. Current research on SHA 2011 is not much. China National Health Development Research Center has analyzed the health costs and financing of chronic noncommunicable diseases in 2010. With the changes in the disease spectrum and social development, we need new evidence about the economic burden of NCDs [29]. Therefore, this paper chooses Dalian's health data, analyses the status of the NCDs spending by SHA 2011, provides health policy advice, gives guidance to other parts of China, and offers a reference basis in China's medical insurance.

\section{Material And Methods}

\section{Data sources}

The data consists of two parts: panel statistical data, including Dalian Health Financial Annual Report, Dalian Statistical Yearbook, China National Health Accounts Report, and Dalian Health Accounts Report from 2017-2019, which were mainly from official sources. Another is patients' medical expenses, which were collected from medical institutions in Dalian by sampling survey.

\section{Study sample}

Multistage stratified cluster random sampling was used in this study. Lottery-style drawings (prefecture-level cities) and computer programing (selection of streets, communities, and towns) are used to select samples for each stage. There were three strata included. To make sure the sample is representative. The sampling proportion was $1 / 3$ for each stratum[30]. The first stratum was to choose sample areas from Dalian city based on considering the perfection of health information management system and the level of economic development. We select nine districts as the sample areas, including Zhongshan, Xigang, Sha Hekou, Lv Shunkou, Gan Jingzi, Jinzhou, Wa Fangdian, Pu Landian, Zhuanghe. Besides, there are Dalian municipal medical institutions and public health institutions. In the second stratum, one general hospital, maternal and child healthcare hospital, Center for Disease Control and Prevention $(C D C)$, and traditional Chinese medicine hospital were selected from each region. Five community health service centers, 20 township health centers, 17 clinics or outpatient departments, and three villages were selected from each district. In the third stratum, a total of 484 health and medical facilities and professional public health institutions were sampled in the selected sample areas according to the categories of health institutions and administrative levels. A total of 408 institutions with valid data were collected, including 48 primary health centers and community service centers, 312 village clinics and clinics, five maternal and child health care centers, five traditional Chinese medicine hospitals, eight specialized hospitals, 22 general hospitals, and 13 public health institutions (five maternal and child health institutions, six CDCs and two other public health institutions). The remaining 76 institutions were abandoned because their data was severely missing or had insufficient data integrity. The basic information for all outpatients and inpatients included age, gender, disease, type of medical institution, type of insured, season, expenditure, region, etc. A total of 12,899,830 valid samples were collected, including 4,215,603 in 2017, 4,304,902 in 2018, and 4,379,325 in 2019. The collected sample data were cleaned and screened according to the International Classification of diseases-10 (ICD-10) code of classification of diseases.

There are multiple diagnoses of the same patient in the survey data. In this study, only the patients with the first diagnosis of NCDs were selected, without considering other complications. 8,104,233 valid items for NCDs were selected, 2,637,681 in 2017, 2,678,359 in 2018, and 2,788,194 in 2019.

\section{Quality control and data management}

Data gathering was classified and coded according to ICD-10. Data extract, audits, cleaning, and calculation were maintained by implementing the basic accounting guidelines of SHA 2011[31]. The National Health Commission of China has trained participants in the data cleansing process. All data were entered electronically into a data terminal connected with STATA version 15.1

(StataCorp, College Station, TX, USA).

\section{Analyses of influencing factors of hospitalization curative care expenditure for NCDs}

A total of 827,513 items of inpatient data was extracted from the whole valid items of NCDs. Expenditures do not conform to a Gaussian distribution but were log-normally distributed. Multiple stepwise regression was used to analyze the influencing factors. 
The independent variables were the year, age, gender, length of stay, medical insurance or not, surgery or not, and institution level. Inclusion criteria were 0.05 , and exclusion criteria were 0.10 . All statistical analyses were performed using STATA version 15.1 (StataCorp, College Station, TX, USA).

\section{Results}

1. The basic situation for NCDs.

In 2017-2019, the current curative expenditure (CCE) for NCDs continued to rise. From 14.205 billion CNY (1 USD $\approx 6.617$ CNY) in 2017 to 18.056 billion CNY in 2019 , it rose $27.11 \%$. Over the same period, the cost of medical care for all diseases increased by $17.86 \%$, from 21.527 to 25.370 billion CNY. (Table 1 ) 
Table 1

Distribution of NCDs expenses in different types of medical institutions from 2017 to 2019 [100 million CNY(\%)]

\begin{tabular}{|c|c|c|c|c|c|c|c|}
\hline \multicolumn{2}{|c|}{ Institutions } & \multicolumn{3}{|l|}{ CCE for NCDs } & \multicolumn{3}{|c|}{ CCE for all diseases } \\
\hline & & Total & Outpatient & Inpatient & Total & Outpatient & Inpatient \\
\hline \multirow[t]{8}{*}{2017} & Hosptial & $122.16(86.00)$ & 27.98(22.90) & $94.19(77.10)$ & 181.47(84.30) & $52.96(29.18)$ & $128.51(70.82)$ \\
\hline & $\begin{array}{l}\text { General } \\
\text { hospital }\end{array}$ & $100.16(70.51)$ & 17.02(16.99) & $83.14(83.01)$ & 153.58(71.34) & $40.47(26.35)$ & 113.11(73.65) \\
\hline & $\begin{array}{l}\text { Traditional } \\
\text { Chinese } \\
\text { medicine } \\
\text { hospital }\end{array}$ & $6.15(4.33)$ & $1.4(22.76)$ & $4.75(77.24)$ & $8.67(4.03)$ & $2.54(29.30)$ & $6.13(70.70)$ \\
\hline & $\begin{array}{l}\text { Special } \\
\text { hospital }\end{array}$ & 15.85(11.16) & $9.56(60.32)$ & $6.30(39.75)$ & $19.22(8.93)$ & $9.95(51.77)$ & $9.27(48.23)$ \\
\hline & $\begin{array}{l}\text { Primary } \\
\text { medical } \\
\text { and health } \\
\text { institutions }\end{array}$ & $11.35(7.99)$ & $8.62(75.95)$ & $2.73(24.05)$ & $19.91(9.25)$ & $11.95(60.02)$ & 7.96(39.98) \\
\hline & $\begin{array}{l}\text { Outpatient } \\
\text { service } \\
\text { agencies }\end{array}$ & $6.26(4.41)$ & $6.26(100.00)$ & $0.00(0.00)$ & $9.31(4.32)$ & $9.31(100.00)$ & $0.00(0.00)$ \\
\hline & $\begin{array}{l}\text { Public } \\
\text { health } \\
\text { agency }\end{array}$ & $2.28(1.61)$ & $1.27(55.70)$ & $1.09(47.81)$ & $4.58(2.13)$ & $3.61(78.82)$ & $0.97(21.18)$ \\
\hline & Total & $142.05(100.00)$ & 44.13(31.07) & $98.01(69.00)$ & $215.27(100.00)$ & 77.83(36.15) & 137.44(63.85) \\
\hline \multirow[t]{8}{*}{2018} & Hosptial & 143.07(89.90) & $36.16(25.27)$ & 106.91(74.73) & $211.29(87.44)$ & $62.5(29.58)$ & $148.79(70.42)$ \\
\hline & $\begin{array}{l}\text { General } \\
\text { hospital }\end{array}$ & $119.29(74.95)$ & $25.67(21.52)$ & $93.62(78.48)$ & $172.26(71.29)$ & $45.77(26.57)$ & $126.48(73.42)$ \\
\hline & $\begin{array}{l}\text { Traditional } \\
\text { Chinese } \\
\text { medicine } \\
\text { hospital }\end{array}$ & $6.12(3.85)$ & $1.61(26.31)$ & $4.51(73.69)$ & $9.91(4.10)$ & $3.21(32.39)$ & $6.7(67.61)$ \\
\hline & $\begin{array}{l}\text { Special } \\
\text { hospital }\end{array}$ & 17.66(11.10) & $8.89(50.34)$ & $8.77(49.66)$ & 29.13(12.06) & $13.52(46.41)$ & 15.61(53.59) \\
\hline & $\begin{array}{l}\text { Primary } \\
\text { medical } \\
\text { and health } \\
\text { institutions }\end{array}$ & $8.78(5.52)$ & $6.65(75.74)$ & $2.13(24.26)$ & $14.15(5.86)$ & 11.8(83.39) & $2.35(16.61)$ \\
\hline & $\begin{array}{l}\text { Outpatient } \\
\text { service } \\
\text { agencies }\end{array}$ & $5.83(3.66)$ & $5.83(100.00)$ & $0(0.00)$ & 8.95(3.70) & $8.95(100.00)$ & $0(0.00)$ \\
\hline & $\begin{array}{l}\text { Public } \\
\text { health } \\
\text { agency }\end{array}$ & $1.47(0.92)$ & $0.44(29.93)$ & $1.03(70.07)$ & $7.23(2.99)$ & $3.76(52.01)$ & $3.47(47.99)$ \\
\hline & Total & $159.15(100.00)$ & 49.08(30.84) & $110.07(69.16)$ & $241.63(100.00)$ & $87.02(100.00)$ & $154.61(100.00)$ \\
\hline \multirow[t]{4}{*}{2019} & Hosptial & $163.11(90.34)$ & $43.20(26.49)$ & $119.9(73.51)$ & $224.48(88.48)$ & $67.69(30.15)$ & $156.8(69.85)$ \\
\hline & $\begin{array}{l}\text { General } \\
\text { hospital }\end{array}$ & $134.16(74.30)$ & $30.99(23.10)$ & 103.16(76.89) & $180.81(71.27)$ & $48.12(26.61)$ & 132.69(73.39) \\
\hline & $\begin{array}{l}\text { Traditional } \\
\text { Chinese } \\
\text { medicine } \\
\text { hospital }\end{array}$ & $9.20(5.10)$ & $2.41(26.20)$ & $6.79(73.80)$ & $13.69(5.40)$ & $4.41(32.21)$ & $9.28(67.79)$ \\
\hline & Special & 19.75(10.94) & $9.80(49.62)$ & $9.95(50.38)$ & 29.99(11.82) & $15.16(50.55)$ & $14.82(49.42)$ \\
\hline
\end{tabular}


hospital

\begin{tabular}{lllllll}
$\begin{array}{l}\text { Primary } \\
\text { medical } \\
\text { and health } \\
\text { institutions }\end{array}$ & $9.88(5.47)$ & $8.60(87.04)$ & $1.28(12.96)$ & $14.19(5.59)$ & $12.73(89.71)$ & $1.46(10.29)$ \\
\hline $\begin{array}{l}\text { Outpatient } \\
\text { service } \\
\text { agencies }\end{array}$ & $5.45(3.02)$ & $5.45(100.00)$ & $0.00(0.00)$ & $6.45(2.54)$ & $6.45(100.00)$ & $0.00(0.00)$ \\
\hline $\begin{array}{l}\text { Public } \\
\text { health } \\
\text { agency }\end{array}$ & $2.12(1.17)$ & $0.66(31.13)$ & $1.46(68.87)$ & $8.57(3.38)$ & $3.91(45.62)$ & $4.66(54.38)$ \\
\hline Total & $180.56(100.00)$ & $57.91(32.07)$ & $122.64(67.92)$ & $253.70(100.00)$ & $90.78(35.78)$ & $162.91(64.21)$ \\
\hline
\end{tabular}

\section{Allocation of CCE in different medical institutions}

In terms of expenditure allocation of medical institutions, NCDs expenditures were mainly concentrated in hospitals. In 2019, it was $90.34 \%$. The CCE for NCDs in general hospitals exceeded $70 \%$ over the three years. Primary hospitals and health institutions continued to decline, and public health institutions accounted for less than $3 \%$. The inpatient expenditures of NCDs were 11.007 billion CNY in 2019 , accounting for $69.16 \%$ of all, higher than the outpatient, 4.908 billion CNY (30.84\%). Compared with the whole disease, the CCE for NCDs in primary hospitals and public health institutions account for a relatively low proportion, and the total inpatient expenditures ratio was significantly higher. (Table 1)

3. Allocation of CCE in the different financing scheme

From 2017 to 2019, out-of-pocket (OOP) expenses for NCDs increased by 0.861 billion CNY, from 4.695 to 5.656 billion CNY, while the proportion decreased by $1.86 \%$, from $33.05 \%$ to $31.16 \%$. The public financing scheme was the most important source of funds for NCDs and whole diseases, and the proportion of NCDs was higher $(63.23 \%$ vs $58.71 \%$ in $2017,61.78 \%$ vs $59.18 \%$ in 2018 , $65.55 \%$ vs $60.14 \%$ in 2019 ). (Table 2 )

Table 2

Distribution of NCDs expenses in different service function from 2017 to 2019 [100 million CNY(\%)]

\begin{tabular}{|lllllll|}
\hline $\begin{array}{l}\text { Service } \\
\text { function }\end{array}$ & \multicolumn{1}{l}{ CCE for NCDs } & \multicolumn{5}{ll}{ CCE for all diseases } \\
\cline { 2 - 6 } & $\mathbf{2 0 1 7}$ & $\mathbf{2 0 1 8}$ & $\mathbf{2 0 1 9}$ & $\mathbf{2 0 1 7}$ & $\mathbf{2 0 1 8}$ & 2019 \\
\hline $\begin{array}{l}\text { Public } \\
\text { financing }\end{array}$ & $89.82(63.23)$ & $98.31(61.78)$ & $118.35(65.55)$ & $126.39(58.71)$ & $143.00(59.18)$ & $152.58(60.14)$ \\
\hline $\begin{array}{l}\text { Social } \\
\text { medical } \\
\text { insurance }\end{array}$ & $9.42(6.63)$ & $10.75(6.76)$ & $13.15(7.28)$ & $7.16(3.33)$ & $16.02(6.63)$ & $19.75(7.78)$ \\
\hline $\begin{array}{l}\text { Government } \\
\text { financing }\end{array}$ & $80.40(56.60)$ & $87.57(55.03)$ & $105.20(58.27)$ & $114.92(53.38)$ & $124.98(52.55)$ & $132.83(52.36)$ \\
\hline $\begin{array}{l}\text { Voluntary } \\
\text { financing }\end{array}$ & $5.28(3.72)$ & $9.01(5.66)$ & $5.94(3.29)$ & $12.66(5.24)$ & $12.95(5.36)$ & $15.25(6.01)$ \\
\hline $\begin{array}{l}\text { Family health } \\
\text { expenditure }\end{array}$ & $46.95(33.05)$ & $51.82(32.56)$ & $56.26(31.16)$ & $87.11(36.05)$ & $85.68(35.46)$ & $85.86(33.84)$ \\
\hline \begin{tabular}{l} 
Total \\
\hline
\end{tabular} & $142.05(100.00)$ & $159.14(100.00)$ & $180.55(100.00)$ & $215.27(100.00)$ & $241.63(100.00)$ & $253.70(100.00)$ \\
\hline
\end{tabular}

\section{Allocation of CCE in different ages}

The age distribution of NCDs shows that before the age of 65, with the increase of age, the CCE keep increasing, reaching the highest level in the 60-64 groups. From 2017 to 2019, it was 1.857, 2.301, 2.532 billion CNY, respectively. After that, the expenditure 
of CCE keep decreasing. The 45-84 age group was the leading group of CCE, and increased more significantly in this group than in other age groups as the years went on. (Fig. 1)

\section{Allocation of CCE in different ICD-10}

Among the 22 categories classified by ICD-10, 15 categories include NCDs. Diseases of the circulatory system was the highest CCE, 3.581 billion CNY in 2017, 4.427 billion CNY in 2018, and 4.913 billion CNY in 2019. Followed by the diseases of the digestive system and Neoplasms. (Table 3)

Table 3

Distribution of NCDs expenses in different ICD-10 from 2017 to 2019 [100 million CNY(\%)]

\begin{tabular}{|llll|}
\hline ICD-10 & 2017 & 2018 & 2019 \\
\hline Neoplasms & $15.99(11.26)$ & $22.53(14.16)$ & $20.64(11.43)$ \\
\hline $\begin{array}{l}\text { Diseases of the blood and blood-forming organs and certain } \\
\text { disorders involving the immune mechanism }\end{array}$ & $1.61(1.13)$ & $0.83(0.52)$ & $0.95(0.53)$ \\
\hline Endocrine, nutritional and metabolic diseases & & & \\
\hline Mental and behavioral disorders & $9.32(6.56)$ & $9.31(5.85)$ & $13.17(7.29)$ \\
\hline Disease of the nervous system & $4.47(3.15)$ & $3.78(2.38)$ & $4.61(2.55)$ \\
\hline Disease of the eye and adnexa & $7.65(5.39)$ & $7.14(4.49)$ & $6.72(3.72)$ \\
\hline Diseases of the ear and mastoid process & $1.87(1.32)$ & $4.77(3.00)$ & $7.25(4.02)$ \\
\hline Diseases of the circulatory system & $1.69(1.19)$ & $2.90(1.82)$ & $1.21(0.67)$ \\
\hline Diseases of the respiratory system & $35.81(25.21)$ & $44.27(27.82)$ & $49.13(27.21)$ \\
\hline Diseases of the digestive system & $10.79(7.60)$ & $9.23(5.80)$ & $10.52(5.83)$ \\
\hline Diseases of the skin and subcutaneous tissue & $24.84(17.49)$ & $24.87(15.63)$ & $28.38(15.72)$ \\
\hline Diseases of the musculoskeletal system and connective tissue & $11.09(7.81)$ & $12.68(7.97)$ & $17.70(9.80)$ \\
\hline Diseases of the genitourinary system & $14.24(10.02)$ & $11.84(7.44)$ & $15.26(8.45)$ \\
\hline Congenital malformations, deformations and chromosomal & $0.92(0.65)$ & $0.52(0.33)$ & $1.14(0.63)$ \\
\hline abnormalities & & & $1.07(0.59)$ \\
\hline Others & $0.21(0.15)$ & $1.24(0.78)$ & \\
\hline
\end{tabular}

6. Influencing factors to inpatient expenditure

Multiple linear regression was used to analyze the influencing factors of inpatient expenditures with NCDs. The included independent variables were the year, gender, age, length of stay, surgery, insurance, and level of the medical institution. There was no collinearity between independent variables and dependent variables. Finally, all independent variables can be included in the regression equation $(P<0.001)$. The linear model can explain the $33.4 \%$ change in total hospitalization expenses. Hospitalization costs increased significantly with increasing years, age, length of stay, and were higher in men, surgery patients, insured patients, and high-level hospitals $(P<0.001)$. The first three factors affecting hospitalization expenses were the length of stay, insurance, and gender. (Table 4). 
Table 4

Regression analysis of influencing factors of hospitalization expenditure

\begin{tabular}{|c|c|c|c|c|c|}
\hline & \multicolumn{2}{|c|}{ Unstandardization Coefficient } & \multirow{2}{*}{$\begin{array}{l}\text { Standardization Coefficient } \\
\text { Beta }\end{array}$} & \multirow[t]{2}{*}{$\mathrm{T}$} & \multirow[t]{2}{*}{ Sig } \\
\hline & $\mathrm{B}$ & S.E & & & \\
\hline Constant & -50.806 & 0.797 & & -63.711 & $\otimes 0.001$ \\
\hline Year & 0.027 & $\otimes 0.001$ & 0.065 & 68.166 & $\otimes 0.001$ \\
\hline Age & 0.002 & $\otimes 0.001$ & 0.107 & 107.259 & $\varangle 0.001$ \\
\hline Gender & 0.007 & $\otimes 0.001$ & 0.185 & 200.983 & $\otimes 0.001$ \\
\hline Length of stay & 0.017 & $\otimes 0.001$ & 0.371 & 410.745 & $\bowtie 0.001$ \\
\hline surgery & 0.292 & 0.001 & 0.370 & 397.848 & $凶 0.001$ \\
\hline insurance & 0.045 & 0.001 & 0.036 & 39.012 & $\varangle 0.001$ \\
\hline Institution level & -0.014 & $\nabla 0.001$ & -0.037 & -38.302 & $\llbracket 0.001$ \\
\hline
\end{tabular}

\section{Discussion}

The impact of NCDs on the health burden is global, and its economic burden is the heaviest of all types of disease. In LMICs, it is simultaneously a rapid growth in NCDs' health and economic burden [3]. In Middle-income countries, such as Russia and India, where the OOP burden of NCD payments is significant. Even in the United States, NCDs are among the most prevalent and costly health conditions [24]. NCDs receive comparatively little attention compared to infectious disease treatment [32]. So far, only four Asian countries, that have published information on NCDs financing [33], and those were years ago, which presents us with a challenge in formulating health policy. This study aims to describe the economic expenditure of NCDs in China and analyze the similarities and differences between different medical institutions, different service functions, different ICD-10 categories, and the influencing factors to inpatient expenditure.

Previous studies show a steady global increase in household expenditure on NCDs from 1999 to 2014 [34]. In 2018, The CCE for NCDs accounted for $65 \%$ of the total CCE. Considering the number of included samples, the average health cost of NCDs may be higher than other diseases. Therefore, we should take more forceful measures to deal with the possible impact of NCDs, which is also the call of The United Nations and WHO [35-36].

This study shows that the CCE of NCDs is related to age. Before the age of 65, the CCE increases with the age increase. Like previous studies, people over the age of 60 are at high risk of NCDs [37-38]. At present, because of the unhealthy lifestyle, 150 million young people smoking, $84 \%$ of teenage girls and $78 \%$ of boys lack physical exercise, $11.7 \%$ of teenagers drink alcohol. At the same time, 41 million children under the age of five are overweight or obese worldwide [3], NCDs are becoming younger. This paper confirms this, with costs rising more for patients younger than 10 in 2019 compared to 2017. Previous studies have shown that high blood pressure and diabetes rise among young people [39-40]. This study found that CCE of NCDs higher group is 45-84 age group. Although the elderly are still the main focus of NCDs, we should not ignore the young, and we should advocate a healthy lifestyle, such as not smoking, drinking less alcohol, and taking more exercise [41-42].

The CCE financing of NCDs mainly comes from public financing scheme. Although the proportion of family health expenditure is lower than total disease and continued to decline, it is still above $30 \%$. Contrary to other studies [6-7], this may be due to higher health expectations among residents of economically developed regions [3]. In recent years, China has adopted some active health policies. In 2013, China's basic medical insurance coverage had reached more than 95\%[43]. In 2017, began to implement Drug zero markup policy [44], in 2018, the national basic Public health benefits have increased from 50 to 55 CNY per person [45]. All this has dramatically reduced household health spending. However, NCDs can cause household poverty [46-47], the proportion of family 
health expenditure is high. We should continue to increase financial support to reduce household spending, especially for hospitalized patients,

In China, high-quality medical resources are mostly concentrated in the 3A (Class Three/Grade A) hospitals. Although graded treatment has been carried out for some years, the results are not significant. People tend to go straight to the 3A hospital [48]. The CCE of NCDs in Dalian city accounts for nearly $90 \%$ in the hospital, higher than that of all diseases, which shows that the hierarchical diagnosis and treatment advocated in China's medical reform is not carried out smoothly. Primary health care, such as primary health care institutions and public health agencies, should be given more responsibility [49]. NCDs have a long course and require frequent medical treatment [9-10]. While $80.00 \%$ of basic medical care can be provided in primary medical and health institutions, more medical resources can be used for NCDs treatment in primary medical and health institutions, which is more costeffective in resource allocation and use [29]. Besides, primary care programs such as family doctors should be promoted by regional characteristics.

For ICD-10 categories, the CCE of the circulation system is highest. On the one hand, it is related to unhealthy lifestyles, such as smoking, lack of exercise, and an unbalanced diet. On the other hand, we have to attach importance to the influence of the environment. Although we think the environment is often associated with respiratory diseases, studies have shown that the deterioration of the environment can increase the incidence of various diseases such as chronic diseases [49]. Therefore, we must pay attention to environmental protection, strengthen the health behaviours throughout the whole life cycle, and establish health programs for key disease populations.

The results of multiple regression analysis showed that length of stay, insurance, and gender were the main factors affecting CCE. The length of stay is related to the severity of the disease and the hospital's efficiency [50]. To control health expenses, the hospital should improve diagnosis and treatment levels and establish common NCDs of the basic norms of evidence-based clinical guidelines [51]. The findings are consistent with research suggesting that men may have a more significant financial burden of NCDs due to unhealthy lifestyle habits [52]. In 2018, the coverage of social and medical insurance in Liaoning province was $94 \%$, full of coverage. However, the results show that the reimbursement rate of NCDs is not high. Considering NCDs' economic burden and mortality rate in all types of diseases, the proportion of NCDs should be increased. Special compensation schemes should be explored and designed for NCDs with high prevalence rates, high treatment frequency, and early control.

\section{Limitation}

Firstly, the bias is caused by the samples. Since the information systems of different medical institutions are not unified, we cleaned and sorted the data as much as possible according to the ICD-10 code. But we believe although part of the data was discarded, the quality of the samples was guaranteed, and the quantity was sufficient to conclude this study. Secondly, only the patients with the first diagnosis of NCDs were selected, without considering other complications, which may have a greater reference value for the major diagnosis of NCDs. Thirdly, as an economically developed area, the results of Dalian city have little real-time reference value to the poor areas.

\section{Conclusion}

The SHA 2011 accounting system can help explain CCE. NCDs still face medical coverage problems and access to medical services in China, and their costs are closely related to the length of stay, and institution level. The government needs to restructure financing, redistribute the costs of NCDs, and rationalize institutional flows and functions.

\section{Abbreviations}

NCDs: Noncommunicable diseases; CCE: Current curative expenditure; SHA 2011: System of Health Accounts 2011; CNY: China Yuan; LMICs: Low-and middle-income countries; CDC: Center for Disease Control and Prevention; WHO: World Health Organization.

\section{Declarations}

\section{Ethics approval and consent to participate}


Because patient identification data was anonymous, the local institutional review board waived the need for patient consent.

\section{Consent for publication}

Not applicable.

\section{Availability of data and material}

All the data relevant for the manuscript are reported in tables. The raw data needs to be approved by the local government.

\section{Competing interests}

The authors have declared that no competing interests exist.

\section{Funding}

This study was supported by National Natural Science Foundation of China (No. 71673299 to Xin Wang)

\section{Authors' Contributions}

Quan Fang and Guoliang Ma designed the whole process and did the pre-research. Quan Fang and Shunli Zhang were the main drafters of the manuscript. Qin Zhang and Xinzhou Xu did some of the expeditionary research. Guoliang Ma and Yuhang Wang contributed the coordination and manuscript editing. Xin Wang was the director for the fund and designed ideas of research. All participated in the analysis and discussion of the topic, under the leadership and instruction of Xin Wang. All authors read and approved the final manuscript.

\section{Acknowledgments}

The authors express thanks to the support of Health Economics Association of Liaoning Province in providing data.

\section{References}

1. Zhou M, Wang H, Zeng X, et al. Mortality, morbidity, and risk factors in China and its provinces, 1990-2017: a systematic analysis for the Global Burden of Disease Study 2017. Lancet. 2019; 394(10204):1145-1158.

2. Global burden of 369 diseases and injuries in 204 countries and territories, 1990-2019: A systematic analysis for the global burden of disease study 2019. Lancet (London, England). 2020;396:1204-1222

3. World Health Organization (WHO). Global status report on noncommunicable diseases 2014. Geneva: World Health Organization; 201

4. Loncar D. Mathers CD, Loncar D. Projections of global mortality and burden of disease from 2002 to 2030. PLoS Med. 2006; 3(11):2011-2030. .

5. Jakovljevic M, Jakab M, Gerdtham U, et al. Comparative financing analysis and political economy of noncommunicable diseases. Journal of Medical Economics. 2019; 22(8):722-727.

6. Allotey P, Reidpath DD, Yasin S, et al. Rethinking health-care systems: a focus on chronicity. 2011; 377(9764): $450-1$.

7. Boutayeb A, Boutayeb S. The burden of non communicable diseases in developing countries. Int J Equity Health. 2005;4(1):2.

8. Lagomarsino G, Garabrant A, Adyas A, et al. Moving towards universal health coverage: health insurance reforms in nine developing countries in Africa and Asia. Lancet. 2012; 380(9845): 933-43.

9. Tefera, Belachew. Are we ready for the rising silent epidemic of metabolic syndrome and chronic non-communicable disease in Ethiopia? Ethiopian Journal of Health Sciences. 2015; 25(1):1-2

10. Fuyong, Hu, Bo, et al. A systematic review of social capital and chronic non-communicable diseases. Bioscience Trends. 2014; 8(6):290-296.

11. Wang Q, Brenner S, Leppert G, et al. Health seeking behaviour and the related household out-of-pocket expenditure for chronic non-communicable diseases in rural Malawi. Health policy and planning. 2015; 30(2):242-52. 
12. World Economic Forum. The Global Economic Burden of Non-Communicable Diseases. Harvard School of Pubic Health. Geneva: World Economic Forum; 2011.

13. United Nations Department of Economic and Social Affairs. Sustainable Development Goal 3: Target 3.8. http://sustainabledevelopment.un.org/sdg3. Accessed May 2, 2020.

14. Horton R. Offline: NCDs-why are we failing? Lancet. 2017; 390(10092):346.

15. Jamison D, Yamey G, Beyeler N, et al. Investing in Health the Economic Case: World Innovation Summit for Health, Doha: Investing in Health Forum, 2016.

16. Beaglehole R, Bonita R. Economists, universal health coverage and non-communicable diseases. Lancet. 2016; 387(10021):848.

17. World Health Organization. Global Health Observatory (GHO) data, cause-specific mortality. http://www.who.int/healthinfo/global_burden_disease/estimates/en/index1.html. Accessed August 23, 2019.

18. Yonel Z, Sharma P, Yahyouche A, et al. Patients' attendance patterns to different healthcare settings and perceptions of stakeholders regarding screening for chronic, non-communicable diseases in high street dental practices and community pharmacy: a cross-sectional study. BMJ Open. 2018; 8(11):e024503.

19. National Bureau of Statistics of People's Republic of China. Statistical communique of the People's Republic of china on the 2016 national economic and social development. http://www.stats.gov.cn/tjsj/zxfb./201702/t20170228_1467424.html. Accesed August 23, 2019.

20. Ministry of Civil affairs of People's Republic of China.Statistical report of the People's Republic of china on the social services development in 2010. http://www.mca.gov.cn/article/zwgk/mzyw/201106/20110600161364.shtml. Accesed May 21, 2017.

21. Li X, Cai L, Cui WL, et al. Association of socioeconomic and lifestyle factors with chronic non-communicable diseases and multimorbidity among the elderly in rural southwest China. Journal of public health.2020;42(2):239-246.

22. Wang NX. Analysis of population aging development in dalian. Liaoning economic statistics :2012(04)

23. Sensenig A. Refining estimates of public health spending as measured in national health expenditures accounts: the United States experience. Journal of Public Health Management \& Practice Jphmp. 2007; 13(2):103.

24. Fong JH. Out-of-pocket health spending among Medicare beneficiaries: Which chronic diseases are most costly? PloS one. 2019; 14(9): e0222539.

25. Davidoff AJ, Erten M, Shaffer T,et al. Out-of-pocket health care expenditure burden for Medicare beneficiaries with cancer. Cancer. 2013; 119(6):1257-65.

26. Yabroff KR, Borowski L, Lipscomb J. Economic studies incolorectal cancer: challenges in measuring and comparing costs. $J$ Natl Cancer Inst Monog 2013;2013(46):62-78.

27. Turner, B. The new system of health accounts in Ireland: what does it all mean? Irish Journal of Medical Science. 2017; 186(3):533-40

28. Bui AL, Lavado RF, Johnson EK, et al. National health accounts data from 1996 to 2010: a systematic review. Bull World Health Organ. 2015; 93(8):566-76D.

29. Zhai TM, Chai PP, Wei Q, et al. Analysis on health cost and financing of chronic noncommunicable diseases in China. Chinese Health Economy. 2014; 33(2):14-17.

30. Zang S, Zhan H, Zhou L,et al. Research on Current Curative Expenditure among Lung Cancer Patients Based on the "System of Health Accounts 2011": Insights into Influencing Factors. J Cancer. 2019; 10(26):6491-6501.

31. OECD, Eurostat, WHO. A system of health accounts 2011-revised edition. Paris: OECD Publishing; 2011.

32. Cameron A, Ewen M, Ross-Degnan D, et al. Medicine prices, availability, and affordability in 36 developing and middle-income countries: a secondary analysis. Lancet. 2009; 373(9659):240-9.

33. Michael E, Kyoko O, Vinodhani NK, et al. Prevention and Control of Selected Chronic NCDs in Sri Lanka: Policy Options and Action. Health, Nutrition and Population (HNP) discussion paper; World Bank, Washington, DC. World Bank.

34. Jaspers, Loes, Colpani, et al. The global impact of non-communicable diseases on households and impoverishment: a systematic review. European Journal of Epidemiology, 2015; 30(3):163-188. 
35. The United Nations. 2011 high-level meeting on prevention and control of non-communicable diseases. http://www.un.org/en/ga/ncdmeeting2011/. Accesed May 21, 2017.

36. World Health Organisation. Global action plan for the prevention and control of NCDs 2013-2020. http://www.who.int/nmh/publications/ncd-action-plan/en/. Accesed May 21, 2017.

37. Chandra A, Gruber J, McKnight R. Patient Cost-Sharing and Hospitalization Offsets in the Elderly. American Economic Review. 2010; 100(1):193-213.

38. Trivedi AN, Moloo H, Mor V. Increased Ambulatory Care Copayments and Hospitalizations among the Elderly. New England Journal of Medicine. 2010; 362(4):320-8.

39. Fazeli Farsani S, van der Aa MP, van der Vorst MM, et al. Global trends in the incidence and prevalence of type 2 diabetes in children and adolescents: a systematic review and evaluation of methodological approaches. 2013; 56(7):1471-1488.

40. De Venecia T, Lu M, Figueredo VM. Hypertension in young adults. Postgrad Med. 2016; 128(2):201-207.

41. Di Daniele N. The Role of Preventive Nutrition in Chronic Non-Communicable Diseases. Nutrients. 2019;11(5):1074.

42. Nakatani H. Global Strategies for the Prevention and Control of Infectious Diseases and Non-Communicable Diseases. $J$ EPIDEMIOL, 2016;264:171-8.

43. Center for Health Statistics and Information of $\mathrm{MOH}$. An analysis report of 2013 National Health Services Survey in China. Beijing: Union Medical University Press; 2015.

44. Ministry of Finance of the People's Republic of China, Circular on comprehensive reform of public hospitals, http://www.mof.gov.cn/zhengwuxinxi/caizhengxinwen/201705/t20170502_2591170.htm. Accesed May 15, 2017.

45. Ministry of Finance of the People's Republic of China, Circular on doing a good job in the national basic public health service project in 2018, http://www.zjwjw.gov.cn/art/2018/8/23/art_1202101_21203672.html. Accesed May 15, 2017.

46. Kankeu HT, Saksena P, Xu K, et al. The financial burden from non-communicable diseases in low- and middle-income countries: a literature review. Health Research Policy and Systems. 2013; 11:31.

47. Hamid F, Pati S, Atun R, et al. Impact of noncommunicable disease multimorbidity on healthcare utilisation and out-of-pocket expenditures in middle-income countries: Cross sectional analysis. PLOS ONE. 2015; 10(7):(e0127199).

48. Hu YY. Abolishing the drawbacks of hierarchical medical system. China Medical Insurance, 2017; (05):5-9.

49. GBD 2016 Healthcare Access and Quality Collaborators. Measuring performance on the Healthcare Access and Quality Index for 195 countries and territories and selected subnational locations: a systematic analysis from the Global Burden of Disease Study 2016. Lancet. 2018;391(10136):2236-2271.

50. Zhou Zhongbin. Analysis of influencing factors of hospitalization days and medical expenses. Naval Medical Journal. 2018;39(06):577-579.

51. Tang YC, Shen G, Hu S L, et al. Status analysis and evaluation of primary clinical guidelines in China. Chinese Journal of Hypertension. 2013; 21(1):48-52.

52. Teh JK, Tey NP, Ng ST. Ethnic and gender differentials in non-communicable diseases and self-rated health in Malaysia. PLoS One. 2014;9(3):e91328.

\section{Figures}




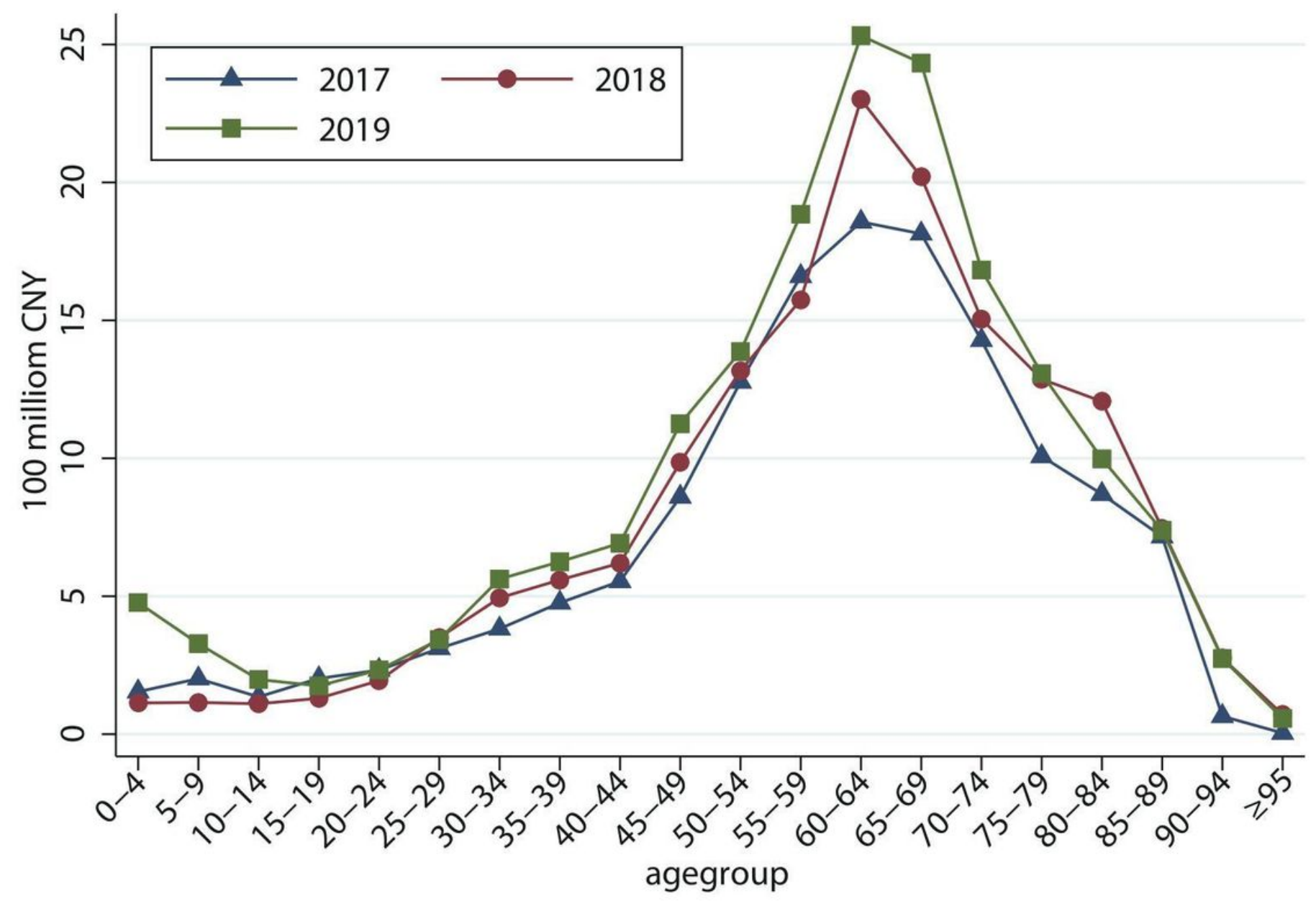

Figure 1

Age distribution of CCE in patients with NCDs, 2017-2019 